\title{
The Essential Unity of the Necessary Being, According to Mulla Abdullah Zanuzi - A Logical Analysis of Zanuzi's Argument FOR ESSENTIAL MONOTHEISM
}

\author{
Shiraz Husain Agha \\ Faculty of Philosophy, Al-Mustafa International University, \\ Qom, I. R. Iran
}

In his works on Islamic philosophy, the divine sage, Mulla Abdullah Zanuzi presented many new arguments for ancient philosophical theories. One of these is his argument for the unity of the essence of the Essentially Necessary Being. This argument rests upon the idea that the Essentially Necessary Being is meta-complete and that there is no necessary connection between multiple instances of the Necessary Being. It is possible to formulate this argument in the following manner: If it were possible for there to be more than one instance for the Essentially Necessary Being, then none of the instances of the Essentially Necessary Being would be meta-complete. However, every instance of the Essentially Necessary Being is meta-complete. In conclusion, it is not possible for there to be more than one instance of the Essentially Necessary Being. Sometimes, in place of the concept, "meta-complete", this sage uses Divine Names, the "Light of lights", the "Secret of secrets" and the "Highest Source" of the universe. Each of these concepts indicates a distinct quality of the Essentially Necessary Being. According to Mulla Abdullah Zanuzi, the objections of ibn Kamunah are incapable of being leveled against his version of the argument or the essential unity of the Essentially Necessary Being.

Keywords: Essential unity, meta-complete, Mulla Abdullah Zanuzi, Light of lights, Secret of secrets, Highest source 


\section{Introduction - Mulla Abdullah Zanuzi}

Mulla Abdullah Zanuzi was born to a certain Birmuqli Baba Khan, in the small village of Zanuz, one of the villages in the outskirts of the Persian city of Marand, close to Tabriz. In his youth, he travelled from his village to the city of Khoy, which was a center of religious knowledge in that age, and began his pursuit of religious education. He began to study Arabic grammar, with all of the various sciences that this contains. His expertise in this field of learning is attested to by the fact that he soon became known as Mulla Abdullah "al-Nahwi" (Mulla Abdullah the Grammarian). Once he had mastered the preliminary Islamic sciences, our sage travelled to the city of Karbala, where he studied the principles of jurisprudence with Agha Sayyid Tabatabai, the author of Kitab al-Riyadh. Following this, he ventured to the city of Qom (Qum) and learnt the book, Qawanin al-Usul from its author, Mirza Qummi. Then, he travelled to the city of Isfahan, where he began his philosophical quest with the divine sage, Mulla Ali Nuri. He also continued his acquisition of the science of jurisprudence with Sayyid Muhammad Baqir Rashti and the principles of jurisprudence with Sayyid Ali Tabatabai. During this time, a certain Haj Muhammad Khan Marwi finished the construction of a religious school named the "Marwi School" in the capital of Iran, Tehran. This person requested Mulla Ali Nuri to come from Isfahan and teach there. However, Mulla Ali Nuri denied the request, as there were nearly two thousand capable students in Isfahan that were learning under him at that time. If he had gone to Tehran, those students would have been left stranded. So, Nuri requested his student, Mulla Abdullah Zanuzi to go in his place to Tehran and teach in the Marwi School. The latter accepted. Soon, Mulla Abdullah Zanuzi gained the special favour of the king and began to be held in great reverence by all. He had taught in that school for nearly twenty years until he passed away in the year 1257. Mulla Abdullah Zanuzi left behind great philosophical and mystical works some of which are as follows: al-Anwar al-Jaliyyah, Risalah al-Iliyyah, Lama'at Ilahiyyah, etc. (Zanuzi 2001: 6-7).

\section{Divine Unity}

There is no doubt that the Essentially Necessary Being is the most important of discussions of Islamic sciences in general and Islamic philosophy in particular. What is more, out of the discussions concerning the Necessary Being, the discussions on His unity are of paramount importance. However, there are many different types of Divine Unity. It would be impossible to discuss all of these in this paper. Hereunder, we will look at some of the 
different meanings of divine unity and specify which one of these will be examined in this paper.

\section{Different Categories of Divine Unity}

Generally, sages and theologians say that there are three basic levels of divine unity. These are the unity of the Divine Essence, the Unity of the Divine Attributes and the Unity of the Divine Act. Hereunder, we will briefly explain what each of these unities mean.

\section{The Unity of the Essence of the Necessary Being}

The unity of Divine Essence means that there is only one individual being that is the instance of the concept, the "Essentially Necessary Being" and that it is impossible for there to be more than one instance for this concept. This is the subject of this paper and it is what Mulla Abdullah Zanuzi attempts to prove in the argument that will be mentioned hereunder. However, sometimes this unity implies that the Essence of the Necessary Being is simple, i.e. that it is not composed of parts (Suyuri 2006: 43).

\section{The Unity of the Attributes of the Necessary Being}

The unity of the attributes of the Necessary Being implies that, even though the attributes of the Necessary Being are conceptually distinct from one another, they share the same instance in the external world. Of course, this extensional unity has been interpreted in different manners, which is something that is outside the scope of this work.

\section{The Unity of the Act of the Necessary Being}

The unity of the divine act could mean one of two things. Sometimes it is taken to refer to the fact that the Necessary Being only has one effect. Other times, it means that all beings of the universe are effects of the Necessary Being.

\section{Mulla Abdullah Zanuzi's Demonstration for the Essential Unity of the Essentially Necessary Being}

It is possible to summarize Zanuzis demonstration in the following manner. This argument comes in the form of a conjunctive exceptive syllogism, the second premise of which is the negation of the consequent of the 
first. In the conclusion, this leads to the negation of the antecedent of the first premise.

First premise: If it were possible for there to be more than one instance for the Essentially Necessary Being, then none of the instances of the Essentially Necessary Being would be meta-complete ${ }^{1}$.

Second premise: However, every instance of the Essentially Necessary Being is meta-complete.

In conclusion, it is not possible for there to be more than one instance of the Essentially Necessary Being.

Like every exceptive syllogism, in order for this syllogism to lead to a certain conclusion, it is necessary for the necessary connection between the antecedent and the consequent of the first premise to be demonstrated. Also, it is necessary for the second premise, i.e. the negation of the consequent to be proven.

Zanuzi demonstrates the necessary connection between the antecedent and the consequent of the first premise by taking recourse to the relation that would exist between the assumed multiple Essentially Necessary Beings. It is possible to summarize his demonstration for the first premise of his argument in the form of a conditional categorical syllogism as follows:

Minor Premise: If it were possible for there to be more than one instance for the Essentially Necessary Being, then there would be no essential connection (i.e. necessary connection) between the assumed multiple Essentially Necessary Beings.

Major Premise: However, if there were no essential (i.e. necessary) connection between the assumed multiple Essentially Necessary Beings, then none of the instances of the Essentially Necessary Being would be meta-complete.

Conclusion: Thus, if it were possible for there to be more than one instance for the Essentially Necessary Being, then none of the instances of the Essentially Necessary Being would be meta-complete.

As can be seen, this conclusion is nothing but the first premise of the argument for the unity of the Essentially Necessary Being mentioned previously. Since this argument has been formulated in the first form of the categorical syllogism, its conclusiveness is self-evident. Therefore, there is

1 The term "meta-complete" was first used by Ibn Sina to refer to the Necessary Being. It implies that God is both complete and the source of the completion of the possible beings of the Universe. 
no need to demonstrate the conclusiveness of the form of this argument. Also, worded in this manner, the argument possesses all of the necessary conditions for the first form - as its minor premise is positive and its major premise is universal. Therefore, from this point of view, the aforementioned argument is unobjectionable. Nevertheless, the contents of the premises of this argument must be proven in order for its epistemological value to be unquestionably asserted. It is possible to do this by proving each of the two premises independently. We can prove the minor premise of this argument, i.e. the idea that "if it were possible for there to be more than one instance for the Essentially Necessary Being, then there would be no essential connection (i.e. necessary connection) between the assumed multiple Essentially Necessary Beings", in the following manner:

Minor premise: If it were possible for there to be more than one instance for the Essentially Necessary Being, then none of the assumed multiple instances of the Essentially Necessary Being would be an effect of the other assumed multiple instances of the Essentially Necessary Being nor would any of them be effects of a common cause.

Major premise: However, if none of the assumed multiple instances of the Essentially Necessary Being were effects of the other assumed multiple instances of the Essentially Necessary Being nor were any of them the effects of a common cause, then there would be no essential connection between the assumed multiple Essentially Necessary Beings.

Conclusion: In conclusion, if it were possible for there to be more than one instance for the Essentially Necessary Being, then there would be no essential connection between the assumed multiple Essentially Necessary Beings.

As can be seen, the conclusion of this argument is nothing but the first premise of the argument mentioned above. However, in order for this argument to be conclusive, it is necessary to show the verity of both of its premises.

It is possible to prove the verity of the minor premise of this argument, i.e. the idea that "if it were possible for there to be more than one instance for the Essentially Necessary Being, then none of the assumed multiple instances of the Essentially Necessary Being would be an effect of the other assumed multiple instances of the Essentially Necessary Being nor would any of them be effects of a common cause", using an exceptive conjunctive syllogism as follows:

First premise: If it were possible for there to be more than one instance for the Essentially Necessary Being but some of the assumed multiple instances of the Essentially Necessary Being were effects of the other assumed multiple 
instances of the Essentially Necessary Being or they were effects of a common cause, then some or all of these assumed instances of the Essentially Necessary Being would be possible beings - as every effect is a possible being.

Second premise: However, no instance of the Essentially Necessary being is a possible being - as possibility and essentially necessity are contradictories and two contradictories cannot combine in a common instance.

Conclusion: Thus, it is not possible for there to be more than one instance for the Essentially Necessary Being and for some of the assumed multiple instances of the Essentially Necessary Being to be effects of the other assumed multiple instances of the Essentially Necessary Being or for them to be effects of a common cause.

It is possible to prove the verity of the major premise of the aforementioned argument, i.e. the idea that "if none of the assumed multiple instances of the Essentially Necessary Being were effects of the other assumed multiple instances of the Essentially Necessary Being nor were any of the effects of a common cause, then there would be no essential connection between the assumed multiple Essentially Necessary Beings", in the following manner:

Principle: When we say that there is an "essential (i.e. necessary) connection" between two things it means nothing but that either one of them is the effect of the other or that they share a common cause. ${ }^{1}$

The converse by contradiction of this principle is that: If neither one of two things is an effect of the other nor are they the effects of a common cause (as is true for the multiple assumed Essentially Necessary Beings), then there will not be an essential connection between them. ${ }^{2}$

Now that the minor premise of the original argument has been demonstrated, we can turn to the explanation of the major premise of that argu-

1 Of course, this is in contrast to some theologians who state that there is no necessary relation between a cause and an effect or two effects of a common cause. Such theologians state that at most, a cause makes the existence of its effect "more likely". However, this is something that has been refuted in its own place.

2 Sometimes it has been asserted that even if neither of two things is the cause of the other nor are they the effects of a common cause it is still possible for there to be an essential and necessary relation between the two. For example, there is a necessary relation between two relative concepts, such the concepts, "that which is up" and "that which is down" even though neither of them are the cause of the other nor are they effects of a common cause. However, more astute sages have pointed out that in this case the two relative concepts are in reality effects of a common cause, the relation that exists between the subjects that are attributed with such relative concepts. So, there can be no necessary relation between two things if the cause-effect relation is not at play. 
ment, i.e. the idea that "if there were no essential connection between the assumed multiple Essentially Necessary Beings, then none of the instances of the Essentially Necessary Being would be meta-complete".

It is possible to prove this premise by using the following argument:

Minor premise: If there were no essential (i.e. necessary) connection between the assumed multiple Essentially Necessary Beings, then the relation between the assumed multiple Essentially Necessary Beings would be one of possibility or impossibility.

Major premise: However, if the relation between the assumed multiple Essentially Necessary Beings were one of possibility or impossibility, then none of the instances of the Essentially Necessary Being would be meta-complete.

Conclusion: Consequently, if there were no essential connection between the assumed multiple Essentially Necessary Beings, then none of the instances of the Essentially Necessary Being would be meta-complete.

Since this argument has been formulated in the first form of the categorical syllogism, its conclusiveness is self-evident. Therefore, there is no need to demonstrate the conclusiveness of the form of this argument. Also, worded in this manner, the argument possesses all of the necessary conditions for the first form - as its minor premise is positive and its major premise is universal. So, from this point of view, the aforementioned argument is unobjectionable. Nevertheless, the contents of the premises of this argument must be proven in order for its epistemological value to be unquestionably asserted. It is possible to do this by proving each of the two premises independently. It is possible to prove the first premise of this argument, i.e. the idea that "if there were no essential (i.e. necessary) connection between the assumed multiple Essentially Necessary Beings, then the relation between the assumed multiple Essentially Necessary Beings would be one of possibility or impossibility", in the following manner:

First remise: If there were no essential connection between the assumed multiple Essentially Necessary Beings but the relation between the assumed multiple Essentially Necessary Beings was not one of possibility or impossibility, then a simultaneous negation of contradictory concepts would entail - as necessity, possibility and impossibility contradict one another.

Second premise: However, the simultaneous negation of contradictory concepts is self-evidently impossible.

Conclusion: If there were no essential connection between the assumed multiple Essentially Necessary Beings, then the relation between the assumed multiple Essentially Necessary Beings would be one of possibility or impossibility. 
Now that the minor premise of this argument has been established, we can turn to its major premise, i.e. the idea that "if the relation between the assumed multiple Essentially Necessary Beings was one of possibility or impossibility, then none of the instances of the Essentially Necessary Being would be meta-complete".

We can prove this idea in the following manner:

Minor premise: If the relation between the assumed multiple Essentially Necessary Beings was one of possibility or impossibility, then none of the assumed instances of the Essentially Necessary Being would be complete.

Major premise: However, if none of the assumed instances of the Essentially Necessary Being were complete, then none of the assumed instances of the Essentially Necessary Being would be meta-complete.

Conclusion: So, if the relation between the assumed multiple Essentially Necessary Beings was one of possibility or impossibility, then none of the instances of the Essentially Necessary Being would be meta-complete.

The minor premise of this argument, i.e. the idea that "if the relation between the assumed multiple Essentially Necessary Beings was one of possibility or impossibility, then none of the assumed instances of the Essentially Necessary Being would be complete", can be proven in the following manner:

First premise: If the relation between the assumed multiple Essentially Necessary Beings was one of possibility or impossibility but all of the assumed instances of the Essentially Necessary Being were complete, then it is self-evident that each of them would possess the perfections of the other assumed instances of the Essentially Necessary Being.

Second premise: However, it is impossible for each of the assumed instances of the Essentially Necessary Being to possess the perfections of the other assumed instances of the Essentially Necessary Being - since in this case the relation between them would be necessity, not possibility, which contradicts the assumption that it is possibility.

Conclusion: If the relation between the assumed multiple Essentially Necessary Beings were one of possibility or impossibility, then none of the assumed instances of the Essentially Necessary Being would be complete.

The major premise of this argument, i.e. the idea that "if none of the assumed instances of the Essentially Necessary Being were complete, then none of the assumed instances of the Essentially Necessary Being would be meta-complete", can easily be proven in the following manner: 
Principle: Every meta-complete being is complete.

The converse by contradiction of this proposition is the following: If something were not complete - such as the assumed instances of the Essentially Necessary Being - then it would not be meta-complete.

This brings the explanation of the first premise of the original argument, i.e. the idea that "if it were possible for there to be more than one instance for the Essentially Necessary Being, then none of the instances of the Essentially Necessary Being would be meta-complete". Now, we can turn to the explanation of the second premise of that argument, i.e. the idea that "every instance of the Essentially Necessary Being is meta- complete". We can prove this verity in the following manner:

First premise: If an instance of the Essentially Necessary Being were not meta-complete, then an instance of the Essentially Necessary Being would not be necessary from all points of view.

Second premise: However, every instance of the Essentially Necessary Being is necessary from all points of view.

Conclusion: Every instance of the Essentially Necessary Being is meta-complete.

The first premise of this argument, i.e. the idea that if an instance of the Essentially Necessary Being were not meta-complete, then an instance of the Essentially Necessary Being would not be necessary from all points of view, can be proven in the following manner:

First premise: If an instance of the Essentially Necessary Being were not meta-complete but every instance of the Essentially Necessary Being was necessary from all points of view, then every instance of the Essentially Necessary Being would be meta-complete - since being meta-complete is a point of view and the assumption is that every instance of the Essentially Necessary Being is necessary from all points of view.

Second premise: The consequent of this premise, i.e. that every instance of the Essentially Necessary Being is meta-complete - is incorrect, as it contradicts the assumption that an instance of the Essentially Necessary Being is not meta-complete.

Conclusion: Thus, the antecedent of the first premise is also incorrect. So, if an instance of the Essentially Necessary Being were not meta-complete, then an instance of the Essentially Necessary Being would not be necessary from all points of view. 
The second premise of this argument, i.e. the idea that "every instance of the Essentially Necessary Being is necessary from all points of view", can be proven in the following manner:

First premise: If every instance of the Essentially Necessary Being was not necessary from all points of view, then some instances of the Essentially Necessary Being would be possible or impossible from some points of view - since necessity, possibility and impossibility are contradictories of one another and it is impossible for contradictories concepts to be simultaneously negated from a single subject.

Second premise: However, it is impossible for some instances of the Essentially Necessary Being to be possible or impossible from some points of view.

Conclusion: Thus, it is impossible for every instance of the Essentially Necessary Being not to be necessary from all points of view. ${ }^{1}$

The truth of the $2^{\text {nd }}$ premise of this argument, i.e. the idea that "it is impossible for some instances of the Essentially Necessary Being to be possible or impossible from some points of view", can be proven in the following manner:

First premise: If some of the instances of the Essentially Necessary Being were possible or impossible from some points of view, then some of the instances of the Essentially Necessary Being would be composed of parts, i.e. necessity and possibility or impossibility. This is because it is impossible for the modes (i.e. necessity, possibility and impossibility) to be one with one another.

Second premise: However, it is impossible for some instances of the Essentially Necessary Being to be composed of parts (Suyuri 2006: 43). This is because everything that is composed of parts needs its parts. However, no Essentially Necessary Being needs anything. Therefore, no Essentially Necessary Being is composed of parts.

Conclusion: So, it is impossible for some of the instances of the Essentially Necessary Being to be possible or impossible from some points of view (Zanuzi 2002: 72).

This brings the explanation of Mulla Abdullah Zanuzis argument to a close. Both of its premises have been fully demonstrated and traced back to the primary propositions that they are founded upon. We can now turn to another matter that this divine sage points to in some of his works.

1 Of course, this does not include those points of view which would lead to the deficiency of the Essentially Necessary Being. 


\section{Mystical and Qur'anic Versions of Zanuzi's Argument}

According to Zanuzi, it is also possible to word the aforementioned argument for the Essential Unity of the Essentially Necessary Being in other, mystical and Qur'anic manners. Zanuzi explicitly states that these terms do not mean the exact same thing as the term, 'meta-complete'; rather, they are only conceptually close to it (Zanuzi 2001: 147). Thus, when we interject these concepts into the previous argument in place of the term 'meta-complete' we should arrive at three new arguments for the unity of the Essentially Necessary Being. Hence, we could word his argument in the following manner:

First premise: If it were possible for there to be more than one instance for the Essentially Necessary Being, then none of the instances of the Essentially Necessary Being would be the Light of lights, the Secrets of secrets and the Highest Source.

Second premise: However, every instance of the Essentially Necessary Being is the Light of lights, the Secrets of secrets and the Highest Source.

In conclusion, it is not possible for there to be more than one instance of the Essentially Necessary Being.

In this version of Zanuzi's argument, instead of the philosophical term 'meta-complete, three mystical-religious concepts are used, i.e. "the Light of lights", "the Secrets of secrets" and the Highest Source. In order for this second version of this argument to be clarified it is necessary to explain what each one of these terms implies. Following this, we will indicate how each one of these Beautiful Names of God can be used to prove His essential unity.

\section{The "Light of Lights"}

The "Light of lights" is a term that was used by Sheikh Ishraq for the Necessary Being (Yazdanpanah 2013: II/80). Obviously, it is impossible to take this to mean that God is a physical light. This is because physical light can be seen. This is while "the visions do not comprehend Him and He comprehends all visions. And, He is Subtle, all-aware". Thus, when we refer to God as a "light" it means something else. Sometimes this Beautiful Name is explained in the following manner: physical light is essentially self-evident and it makes things that are not essentially evident, evident. That is, physical light allows things which are not essentially luminous and evident to be seen and known by the faculty of vision. In other words, physical light allows such things to acquire mental existence in the faculty of vision. In the same manner, existence is essentially real and it makes 
things that are not essentially real, real. That is to say, existence allows things which are not essentially existent to exist, either in the mind or the external world. So, existence is similar to physical light. Since God has existence it is possible to refer to Him as "light". However, He is not simply a light; rather, He is the "Light of lights". This could mean one of two things. First of all, it could mean that His luminosity is more intense than the luminosity of other things. Now, the Necessary Being is sheer existence. Meaning, He is not a quiddity that has existence; rather, He is sheer existence. Also, He is pure existence. Meaning, $\mathrm{He}$ is not existence that is coupled with non-existence. Therefore, He is sheer and pure existence. So, His luminosity is more intense than that of other things (Zanuzi 2003: 71). However, God's being the "Light of lights" could also refer to something else, i.e. the fact that His luminosity illuminates other lights. In philosophical terms, it means that His existence brings other beings into existence. To be more precise, even though all existence, even the existence of a possible being, is essentially real and existent this does not free it from the need for an agent. Meaning, possible existence does not need a condition in order to come into existence, as quiddity does. However, it does need an agent. However, Necessary existence does not need a condition or an agent to come into existence. So, His existence brings other beings into existence and His light illuminates other lights.

Having said this, it is possible to understand what the argument of Mulla Abdullah Zanuzi means when the term 'meta-complete' is replaced with the term "Light of lights". We can formulate this argument as follows:

First premise: If it were possible for there to be more than one instance for the Essentially Necessary Being, then none of the instances of the Essentially Necessary Being would be the Light of lights. This is because in this case, each one of the instances of the Essentially Necessary Being would not be sheer existence, as it would lack the perfections of the other instance or instances of this concept. Also, in this case, each instance would only be the agent of the possible beings that were its own effects, not the agent of the possible beings that were the effects of the other instance or instances of this concept. So, if it were possible for there to be more than one instance for the Essentially Necessary Being, then none of the instances of the Essentially Necessary Being would be the Light of lights.

Second premise: However, every instance of the Essentially Necessary Being is the Light of lights. This is because the Essentially Necessary Being is necessary from all aspects, one of which is His being the Light of lights.

In conclusion, it is not possible for there to be more than one instance of the Essentially Necessary Being. 


\section{The "Secret of Secrets"}

Secrets are unknown by all, save for a few. In essence, every instance of the reality of existence is unknown for the mind. This is because external reality is essential for the reality of existence (Mutahhari 1994: 37). So, if it entered the mind it would mean that either the mind and external reality would unite together or existence would lose one of its essential properties (Tabatabai 2003: I/82). However, both of these alternatives are incorrect. Hence, the reality of existence cannot enter the mind and thus it cannot be known by it. Since the Essentially Necessary Being possesses existence, His existence cannot be known by the mind. Thus, His existence is a secret that is hidden from the mind. However, there is a fundamental difference between the existence of the Necessary Being and the existence of other, possible beings. This is because other beings are limited and possess quiddities. So, even though their existences are incapable of being known by the mind, their quiddities can be known by the mind. This is because external reality is not essential for quiddity. So, the aforementioned problem does not arise for it. Moreover, possible beings are limited in their existences. Since they are limited, the heart is capable of intuitively grasping them by means of knowledge by presence - even though the mind cannot understand them through acquired knowledge. However, since God is sheer existence He does not possess quiddity and is unlimited in His being. So, He does not have a quiddity that might be understood by the mind. Also, the heart is incapable of grasping His unlimited existence in its entirety is through knowledge by presence (Misbah Yazdi 1999: 398). Thus, His secrecy is more intense than that of other beings. So, He is the "Secret of secrets". Having understood this, we can now turn to the argument of Mulla Abdulla Zanuzi for divine unity. It is possible to insert the abovementioned Name of God into this argument and formulate it in the following manner:

First premise: If it were possible for there to be more than one instance for the Essentially Necessary Being, then none of the instances of the Essentially Necessary Being would be the "Secrets of secrets". This is because in this case each of the instances of the Essentially Necessary Being would be limited. If it were limited then it would possess quiddity that was capable of being known by the mind and an existence that was capable of being directly grasped by the heart. In this case, none of the instances of the Essentially Necessary Being would be the "Secrets of secrets".

Second premise: However, every instance of the Essentially Necessary Being is the "Secrets of secrets". This is because every instance of the Essentially Necessary Being is necessary from all aspects, one of which is its being the "Secrets of secrets". 
In conclusion, it is not possible for there to be more than one instance of the Essentially Necessary Being.

\section{The "Highest Source"}

Physical loftiness cannot be ascribed to the Necessary Being as $\mathrm{He}$ is not a physical body and therefore does not exist in any place or time. However, metaphysical loftiness is capable of being ascribed to Him. In this meaning of the term, loftiness implies that something has power over something else. Since every cause has power over its effect, it is possible to say that every cause is above, higher and loftier than its effect. Now, the Essentially Necessary Being is the cause of all beings. Thus, He is higher than all beings and is the source of their existence (Rahman 1975: 75). Thus, He is the "Highest Source" of all beings. When we interject this Beautiful Name of God into Mulla Abdulla Zanuzi's argument for divine unity, it manifests itself as follows:

First premise: If it were possible for there to be more than one instance for the Essentially Necessary Being, then none of the instances of the Essentially Necessary Being would be the "Highest Source". This is because in this case, each one of the instances of the Essentially Necessary Being would only be the cause of its own effect, not the effects of the other Essentially Necessary Beings. So each one of them would only have power over its own effects, not the effects of the other Essentially Necessary Beings. In this case, each one of them would only be higher than its own effects, not the effects of the other instances of the Essentially Necessary Being. Consequently, none of the Essentially Necessary Beings would be the Highest Source of existence.

Second premise: However, every instance of the Essentially Necessary Being is the "Highest Source". This is because being the Highest Source of existence is an instance of perfection and every Essentially Necessary Being necessarily possesses all aspects of perfection. So, every Essentially Necessary Being is the Highest Source of existence.

In conclusion, it is not possible for there to be more than one instance of the Essentially Necessary Being.

\section{Objections to the Arguments for the Essential Unity of the Necessary Being}

Generally speaking, Muslim philosophers did not raise many objections to the arguments for the unity of the Divine Essence. There are, however, a few exceptions to this general rule, one of which is the famous objection of the sage, ibn Kamunah (Sabziwari 2011: III/514). However, this objec- 
tion is directed to one of the famous arguments for the Essential Unity of the Necessary Being called, the Demonstration of Composition. According to Mulla Abdullah Zanuzi, the objection of ibn Kamunah is not capable of being leveled against his own version of the argument for the unity of the Divine Essence. Hereunder, we will briefly examine ibn Kamunah's objection and then examine why Mulla Abdullah Zanuzi's argument is secure from it.

\section{Ibn Kamunah's Objection to the Philosophers' Argument for the Unity of the Divine Essence}

Traditionally, philosophers and theologians have stated that if there were more than one instance of the Necessary Being, then each of these instances would be composed of parts. This is because each of these instances would share something in common, i.e. the attribute of essential necessity. Each of them would also have to possess a distinction. This is because without distinction there can be no multiplicity. At the same time, that which multiple things share in common cannot be the same as that which makes them distinct from one another. Thus, each of them would be composed of parts, i.e. that which they share in common and that which makes them distinct. However, no instance of the Necessary Being can be composed of parts. This is because everything that is composed of parts depends in its existence on those parts. However, no Necessary Being is dependent on something else in its existence. So, no Necessary Being is composed of parts. Thus, it is impossible for there to be more than one instance of the Necessary Being.

The sage ibn Kamunah objected to this argument in the following manner: There is no necessary connection between the antecedent and the consequent of the first premise of this argument. This is because it is possible for the multiple instances of the Necessary Being to be completely distinct from one another in the external world and not to share anything in common. Thus, they would not be composed of parts. However, the attribute of "the necessity of existence" may be considered to be an abstract concept that has no reality in the external world but which the mind derives from these completely distinct beings.

\section{The Infallibility of the Mulla Abdullah Zanuzi's Argument for the Unity of the Divine Essence}

Even though many philosophers have answered the aforementioned objection of ibn Kamunah (Tabatabai 2010: 196), according to Mulla Abdullah Zanuzi, this objection is not capable of being leveled against his own argument for the Divine Unity. Meaning, there is no need for him to answer 
it since it does not even arise with respect to his own argument. This is because, even if we say that it is possible for the mind to abstract a single concept from completely distinct beings that share no real attribute with one another, each of the completely distinct instances of the Necessary Being would still be incomplete in that each of them would lack the perfections of the other instance of the Necessary Being. So, none of them would be complete, meta-complete, the Light of lights, the Secret of secrets and the Highest source of the universe. Thus, Mulla Abdullah Zanuzi's argument for the unity of the Divine Essence is secure from the objections of ibn Kamunah and its conclusiveness cannot be denied.

\section{Conclusion}

Mulla Abdullah Zanuzi was a great philosopher who presented many innovative arguments and explanations for some of the ancient philosophical axioms of Islamic wisdom. One of these is his argument for the unity of the Divine Essence. This argument rests upon the idea that the Essentially Necessary Being is meta-complete and that He is the Light of lights, the Secret of secrets and the Highest source of the Universe. It is also founded upon the idea that the Essentially Necessary Being is necessary from all aspects. According to this divine sage, this argument is infallible and the objections that are capable of being leveled against other arguments for the divine unity are incapable of being leveled against his own.

Received: August $16^{\text {th }}, 2019$.

Accepted: November 22 $2^{\text {nd }}, 2019$.

\section{References}

Mutahhari, Murtada (1994), Sharh Mukhtasar Manzumah, Tehran, Sadra.

Rahman, Fazlur (1975), The Philosophy of Mulla Sadra, New York, SUNY.

Sabziwari, Mulla Hadi (2011), Sharh al-Manzumah, Beirut, the Arabic History Publishing and Distribution.

Suyuri, Miqdad (2006), al-Nafa' Yawm al-Hashr fi Sharh Bab al-Hadi al-Ashar, Qom, Jami'a al-Mudarrisin.

Tabatabai, Muhammad Husain (2003), Nihayah al-Hikmah, Qom, Muassisah Amuzishi wa Pajuhishi Imam Khomeini.

Tabatabai, Muhammad Husain (2010), Bidayah al-Hikmah, Qom, Jami'a al-Mudarrisin. 
Yazdanpanah, Sayyid Yadullah (2013), Hikmat Ishraq, Qom, Samt.

Misbah Yazdi, Muhammad Taqi (1999), Amuzesh Falsafah, Tehran, Sazman Tablighat Islami.

Zanuzi, Mulla Abdullah (2001), Lama'at al-Ilahiyyah, Tehran, Intisharat Mu'assisah Pajuhishi Hikmat wa Falsafah Iran.

Zanuzi, Mulla Abdullah (2002), Muntakhab Khakani fi Kashf Haqa’iq Irfani, Tehran, Intisharat Mawla.

Zanuzi, Mulla Abdullah (2003), Anwar Jaliyyah, Tehran, Amir Kabir. 